\title{
The retrograde continence enema in children with spina bifida: not as effective as first thought
}

\section{Original Article}

Sebastian K. King ${ }^{\text {a, b, c }}$, Lefteris Stathopoulos ${ }^{a}$, Loreto Pinnuck ${ }^{d}$, Judy Wells e, John Hutson ${ }^{\text {b, c, f }}$ and Yves Heloury ${ }^{f}$

a Department of Paediatric Surgery, The Royal Children's Hospital, Melbourne, Victoria, Australia

b Surgical Research Laboratory, Murdoch Childrens Research Institute, Melbourne, Victoria, Australia

${ }^{c}$ Department of Paediatrics, University of Melbourne, Victoria, Australia

d Department of Stoma Therapy, Monash Medical Centre, Melbourne,

Victoria, Australia

e Department of Stoma Therapy, The Royal Children's Hospital, Melbourne, Victoria, Australia

f Department of Urology, The Royal Children's Hospital, Melbourne, Victoria, Australia

Correspondence to:

Dr Sebastian King PhD FRACS

Department of Paediatric Surgery

The Royal Children's Hospital

50 Flemington Road

Parkville, Melbourne, Victoria

Australia 3052

(P) +6139345 5522

This is the author manuscript accepted for publication and has undergone full peer review but has not been through the copyediting, typesetting, pagination and proofreading process, which may lead to differences between this version and the Version of Record. Please cite this article as doi: $10.1111 /$ jpc. 13408

This article is protected by copyright. All rights reserved. 
(F) +61393456668

(E) sebastian.king@rch.org.au

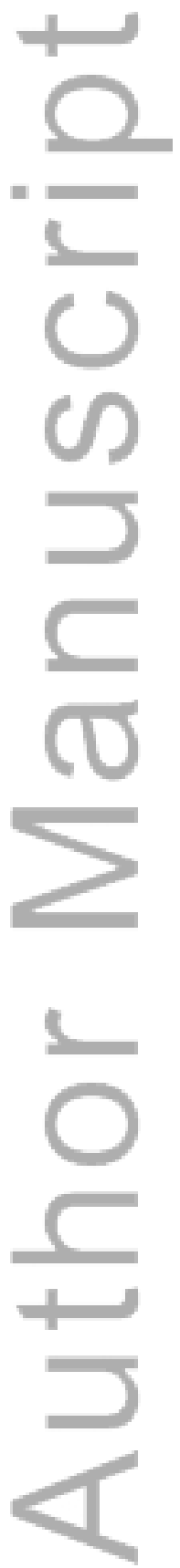

This article is protected by copyright. All rights reserved. 


\section{The retrograde continence enema in children with spina bifida: not as effective as first thought}

\section{Original Article}

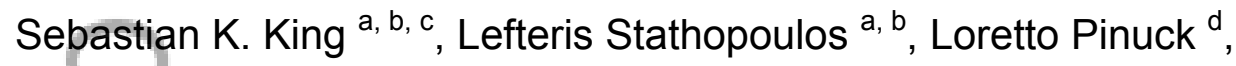
Judy Wells ${ }^{e}$, John Hutson ${ }^{b, c, f}$ and Yves Heloury ${ }^{f}$

a Department of Paediatric Surgery, The Royal Children's Hospital, Melbourne, Victoria, Australia

b Surgical Research Laboratory, Murdoch Childrens Research Institute, Melbourne, Victoria, Australia

${ }^{c}$ Department of Paediatrics, University of Melbourne, Victoria, Australia

d Department of Stoma Therapy, Monash Medical Centre, Melbourne,

Victoria, Australia

e Department of Stoma Therapy, The Royal Children's Hospital, Melbourne, Victoria, Australia

f Department of Urology, The Royal Children's Hospital, Melbourne, Victoria, Australia

Correspondence to:

Mr Sebastian King PhD FRACS

Department of Paediatric Surgery

The Royal Children's Hospital

50 Flemington Road

Parkville, Melbourne, Victoria

Australia 3052

(P) +6139345 5801

(F) +61393456668

(E) sebastian.king@rch.org.au 


\section{Abstract}

Aims: To investigate the effectiveness of Peristeen retrograde continence enema (RCE) in the management of faecal incontinence in children with spina bifida.

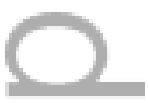

Methods: We identified an homogenous group of spina bifida patients in whom RCE was initiated (01/2006 - 07/2013). Confidential assessments included: (1) Fecal Incontinence Quality Of Life (FIQOL), (2) St Marks Faecal Incontinence score, (3) Cleveland Clinic Constipation score, and, (4) Neurogenic Bowel Dysfunction score.

Results: $11 / 20$ patients (mean age $14.5 \pm 5.3$ years) were male. 9/20 patients were still using RCE (mean follow-up 4.1 years). Three patients ceased RCE within ten days, six after 4-12 months, and two after 36-48 months. Reasons for cessation included balloon difficulties $(n=4)$, procedure deemed too difficult $(n=4)$, and pain $(n=3)$.

There were no differences between the groups in length of training time for technique, instillate fluid/volume used, and time taken to perform RCE. There were no differences between the groups for quality of life, faecal incontinence or constipation scores.

Conclusions: We demonstrated a high rate of cessation with the RCE in patients with spina bifida. This could not be explained by associated 
conditions, or by enema-related parameters. One possible explanation is the lack of on-going outpatient support for the children and their families.

Keywords: spina bifida, retrograde continence enema, Peristeen, faecal incontinence

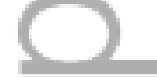

l.

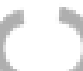

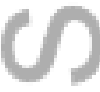

D

с

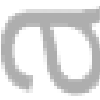

$>$
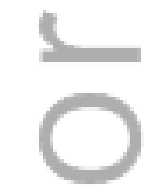

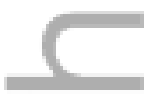

$+$

(

$\varangle$

This article is protected by copyright. All rights reserved. 
What is already known on this topic

(1) Children with spina bifida are commonly affected by faecal and urinary incontinence.

(2) The management of faecal incontinence in spina bifida is complex;

hence the existence of multiple non-operative and operative interventions.

(3) Faecal incontinence may have a significant impact upon the quality of life in affected children.

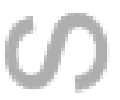

\section{What this paper adds}

(1) The retrograde continence enema may be effective in the management of faecal incontinence in a select population of children with spina bifida.

(2) Success with the retrograde continence enema relies upon parental and patient compliance.

(3) The current study focused upon an homogenous selection of patients, unlike the majority of similar studies published in the literature.

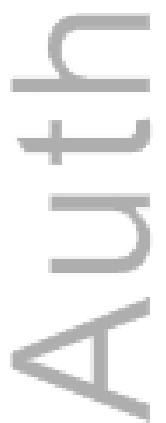

This article is protected by copyright. All rights reserved. 


\section{Introduction}

Faecal incontinence affects the majority of children with spina bifida. [1] As the neurological abnormalities are life-long it is important to provide a mechanism for both the patient and their family to manage the incontinence. The psychological impact of faecal incontinence upon a child is potentially significant. [2] Consequently, the treatment regimen to manage the incontinence must be effective, but also tolerable.

Spina bifida patients may manage faecal incontinence in a number of ways. Unfortunately, the administration of oral medications often has a limited role. [3] Whilst the use of PEG3350 has increased over the last decade with greater evidence of its effectiveness in patients with idiopathic constipation, its role in the management of spina bifida patients remains unclear. [4]

The antegrade continence enema (ACE), administered via a caecostomy, was first described in 1990 by Malone et al. [5] The ACE has been shown to effectively treat faecal incontinence and chronic constipation in both children and adults. The most common indication for the ACE has been spina bifida. [6-9] However, as effective as this treatment regimen has proven to be, it requires an operation to form the appendicostomy or caecostomy. It is also associated with short and long term complications, including recurrent infections and possible creation of a false passage. [10]

The retrograde colonic enema (RCE) has been used effectively for many centuries. Shandling and Gilmour, at the Hospital for Sick Children Toronto, demonstrated its role in children with spina bifida over 25 years ago. [11] Since then there have been numerous modifications to improve the efficacy of this treatment modality. Whilst there is some evidence in the adult 
literature of the effectiveness of RCE [12], the evidence for the paediatric population is less impressive and in more heterogenous patient populations. $[3,13-15]$

We investigated the effectiveness of the Peristeen system (Coloplast, Mount Waverley, Victoria, Australia) in the management of faecal incontinence in children with spina bifida. Peristeen is an enclosed catheter system with a pre-coated catheter and a soft, inflatable balloon. The balloon catheter is placed through the anus into the rectum, and then gently inflated to create a seal. Irrigation fluid is then passed through the catheter into the rectum, with a resultant retrograde colonic washout. This aims to provide the patient with an empty distal colon and rectum until the next washout, thus reducing the risk of faecal incontinence. By focusing upon a patient group with a unifying diagnosis we wished to clearly show the outcomes for that condition alone.

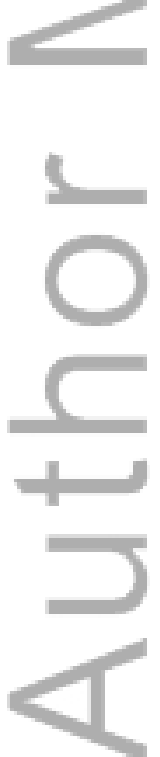

This article is protected by copyright. All rights reserved. 


\section{Materials and Methods}

All patients with spina bifida in whom Peristeen had been initiated between January 2006 and July 2013 were identified. All patients had failed more conventional forms of bowel management, including dietary modifications and oral laxative therapies and suppositories. Patients were managed at either The Royal Children's Hospital or Monash Medical Centre by the senior author $(\mathrm{YH})$. An independent investigator (SKK), not involved in patient care, contacted patient families following ethical approval from both hospitals (RCH HREC 33107A, MMC HREC 14079X). Following informed consent with the parent or carer, confidential phone interviews were conducted. The data were entered into a Microsoft Excel programme (Microsoft, Seattle). All information was cross-referenced with hospital systems to ensure accuracy.

Thirty-three patients with spina bifida, in whom Peristeen was trialled, were identified. The information collected included: (1) diagnosis, (2) presence of ventriculoperitoneal shunt, (3) ventriculoperitoneal shunt revision(s), (4) associated anomalies, (5) presence of urinary incontinence, (6) management of urinary incontinence, (7) degree of mobility, (8) age at commencement of Peristeen, (9) time taken to train technique, (10) fluid used, (11) fluid volumes used, (12) duration of use, (13) complications, (14) cessation of use, and, (15) reasons for cessation.

Multiple assessments of quality of life, continence and constipation were conducted. These included: (1) Fecal Incontinence Quality Of Life (FIQOL) [16], (2) St Marks Faecal Incontinence score [17], (3) Cleveland Clinic Constipation score [18], and, (4) Neurogenic Bowel Dysfunction score. 
[19] Pseudocontinence was defined as no involuntary stool loss in the preceding six months, as per Vande Velde. [13] The FIC QOL was also collected for all patients for future prospective analysis. [20]

The FIQOL scale comprises four quality of life scales, including lifestyle, coping/behaviour, depression/self-perception, and embarrassment. It has been shown to be both a reliable and valid measure in adult populations. The St Marks Incontinence score focuses upon aspects of faecal incontinence, including: (1) incontinence of solid, liquid and gas, (2) alterations in lifestyle, (3) the need for a pad, (4) the requirement for constipating medications, and, (5) an inability to defer defaecation.

The Cleveland Clinic Constipation score assesses the severity of the patient's constipation. It contains eight parameters, including frequency of bowel movements, straining, completeness of evacuation, abdominal pain, time per attempt at evacuation, type of assistance, number of unsuccessful attempts, and duration of constipation. It has been validated in adult populations. The Neurogenic Bowel Dysfunction score is a validated symptom-based score developed specifically in spinal cord injury patients with neurogenic bowel dysfunction. The score focuses upon background parameters, faecal incontinence, constipation, obstructed defaecation, and impact upon quality of life. It has been used in both paediatric and adult populations.

The mean and standard deviation (SD) are presented for symmetric data, while for skewed data the median and interquartile ranges (IQR) are shown. Differences in means between study arms were assessed using a two-sample t-test. A Mann-Whitney test was performed on skewed data. 
Dichotomous outcomes were compared with the Fisher exact test. A p-value $<$ 0.05 was considered as significant.

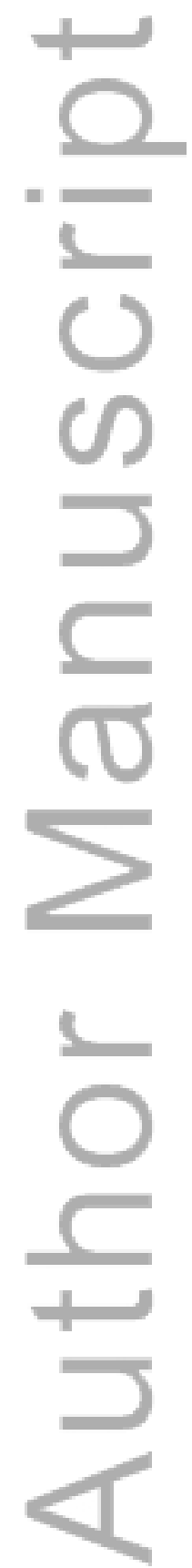

This article is protected by copyright. All rights reserved. 


\section{Results}

Interviews were conducted with 20/33 families. The remaining 13 families were either unable to be contacted, or unable to perform the questionnaire over the phone due to language difficulties. Interviews were performed with the patient's mother in $15 / 20$, the patient's father in $5 / 20$, and lasted $45-60$ minutes.

Of the 20 children, 11 were male. The mean age at time of interview was $14.5 \pm 5.3$ years. The mean follow-up period was 4.1 years $(1-8$ years). The comparison between those patients still using Peristeen and those patients no longer using Peristeen is displayed in Table 1. The results obtained for both groups for FIQOL, St Marks Incontinence score, Cleveland Clinic Constipation score and Neurogenic Bowel score are displayed in Table 2.

There was a preponderance of males in the group in whom Peristeen was successful (7/11 [64\%] versus $2 / 9$ [22\%]). The two groups were similar with regards to their ages at time of interview $(p=0.44)$ and those patients still using Peristeen commenced therapy at a younger age, though this was not statistically significant $(p=0.23)$. All patients had urinary incontinence and, in the majority, this was managed using $\mathrm{CIC}$ via the native urethra. There were no differences between the two groups with regards to length of time training for the technique, the instillate fluid and volume used, and the time taken to perform the regimen. There was a significant difference between the two groups in the time period for which Peristeen was employed $(p=0.001)$. Those still using Peristeen were more dependent upon others for assistance than those that ceased to use the technique (7/9 [78\%] versus $4 / 11$ [36\%]). 
There were no differences between the scores obtained for the two groups with regards to FIQOL, St Marks Faecal Incontinence, Cleveland Clinic Constipation and Neurogenic Bowel Dysfunction. Eight out of nine patients using Peristeen achieved pseudocontinence, while one remained incontinent. Among those patients that ceased to use Peristeen, 5/11 subsequently achieved pseudocontinence: three after migrating to ACE, two by conventional therapies (diet, suppositories). Six patients had persisting faecal incontinence. The reasons for ceasing to use Peristeen were: difficulties with the balloon $(n=4)$; procedure described as too difficult and invasive $(n=3)$ or painful $(n=3)$; and one patient stopped after experiencing vasovagal episodes. Three patients ceased using Peristeen within one week of commencement of the treatment.

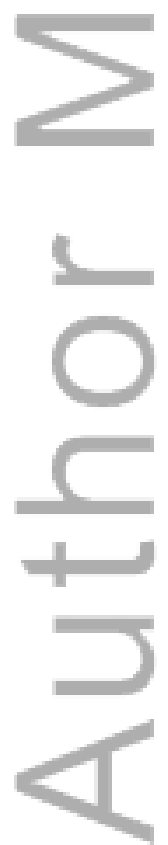




\section{Discussion}

Colonic enemas, either retrograde or antegrade, are valuable treatment options for faecal incontinence caused by congenital malformations affecting the spinal cord or the anorectum. $[13,21]$ In adults with central nervous system diseases, there are no current evidence-based recommendations for faecal incontinence management. [22] Current management favours an individually-tailored, stepwise approach: typically, a form of RCE, in our study Peristeen, is part of a conservative bowel management and is trialled after failure of conventional treatment, including toileting routines and laxatives. [13, 23] Surgical procedures, including formation of appendicostomy, resection of megarectosigmoid or formation of colostomy, may be considered in patients unsuccessfully managed conservatively. [24] In patients with spina bifida and faecal incontinence, the evidence for efficacy of the RCE is based upon observational studies. [12]

In our current study of a select group of patients with spina bifida, 33 were offered Peristeen to treat faecal incontinence. Of 20 patients interviewed 11 had ceased to use Peristeen, a higher rate of failure than typically reported. In comparison, Shandling et al. and Vande Velde et al. reported respectively $4 / 112$ and $5 / 116$ cessations of retrograde colonic enemas in cohort studies of patients with spina bifida and faecal incontinence. [9, 13] Our results more closely resemble those of Liptak et al., where 15/31 children had stopped using RCE at the end of a 30-month follow-up. [25] Interestingly, of the 15 children, six ceased in the first three weeks. In our cohort, $3 / 11$ ceased within one week of commencing the treatment. 
The distributions of neurological and neurosurgical associated anomalies, urinary incontinence, and mobility were the same in both our groups. Moreover, there were no differences in the age at commencement of Peristeen, nor the time spent training, in accordance with other studies. [13, 26] Volume of irrigation and type of instillate used, as well as time spent on irrigation, were similar between both groups, again consistent with previous studies. [27]

Harari et al. [28] demonstrated in a randomized controlled trial that a structured, nurse-led assessment, leading to a targeted treatment of faecal incontinence and constipation in stroke patients, improved symptoms of bowel dysfunction. Although difficult to measure or to demonstrate, regular follow-up and easy availability of professional medical or psychological support could be important components for a successful management of faecal incontinence. [13] In our cohort, there were no significant differences in the various scores used to assess bowel dysfunction between the two groups: as the severity of faecal incontinence is similar, reasons for cessation could be subjective. In our institutions, multidisciplinary teams manage children with spina bifida, including specialized stoma therapists. A difference between the needs of our cohort and the available supports for on-going therapy and troubleshooting could be an explanation for our high rate of failure. Unfortunately, the quality of the follow-up was not captured by our questionnaires.

According to a review by Vande Velde, pseudocontinence was achieved in $80 \%$ of patients using RCE. [29] Although spina bifida was the underlying condition in the majority of patients pooled, miscellaneous conditions were considered. In our study, 8/9 patients still using Peristeen 
achieved pseudocontinence. This rate is compatible with the overall statement that RCE has a high efficacy in carefully selected patients. [9] Unfortunately, there are no randomized controlled studies in spina bifida patients to assess the efficacy of RCE against another form of treatment. However, the RCE was found superior to conservative bowel management in a randomized control trial in spinal cord-injured adults. [30]

A number of our patients who ceased using Peristeen were able to achieve pseudocontinence after an ACE procedure or by employing conventional therapies (diet, suppositories). Matsuno et al. [31] compared RCE to the ACE procedure in a retrospective study in children with spina bifida. Rates of faecal pseudocontinence were similar, 10/13 (77\%) and 9/12 $(75 \%)$ respectively. However, they found that procedural independence was higher in the antegrade group. In our study, patients of both groups showed a certain degree of dependence.

Limitations of our study were that it was retrospective and, as already mentioned, $13 / 33$ were either lost to follow-up or unable to answer the questionnaires. Consequently, our cohort is small: statistical significance should be considered with caution. However, few studies report a high rate of unsuccessful management with RCE, so that this group is rarely characterized. In addition, few studies have focused on a homogenous group of spina bifida patients.

In conclusion, our study of the effectiveness of RCE in the management of faecal incontinence in children with spina bifida demonstrated a high rate of cessation. This could not be explained by associated conditions nor enema-related parameters. One possible explanation is the lack of on- 
going outpatient support for the child and their family. The RCE remains an important option prior to surgery. However, long-term follow-up studies and randomized control trials comparing RCE and conventional treatments are needed to establish the true efficacy of the RCE.

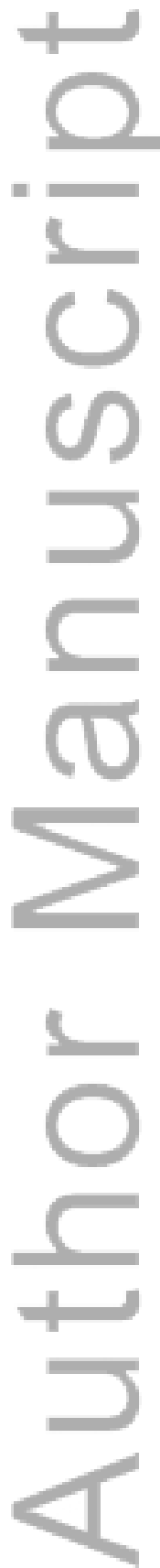

This article is protected by copyright. All rights reserved. 


\section{Acknowledgements}

Sebastian King is the proud recipient of a Career Development Award from the Murdoch Childrens Research Institute and the Senior Lecturer Fellowship from the Royal Australasian College of Surgeons.

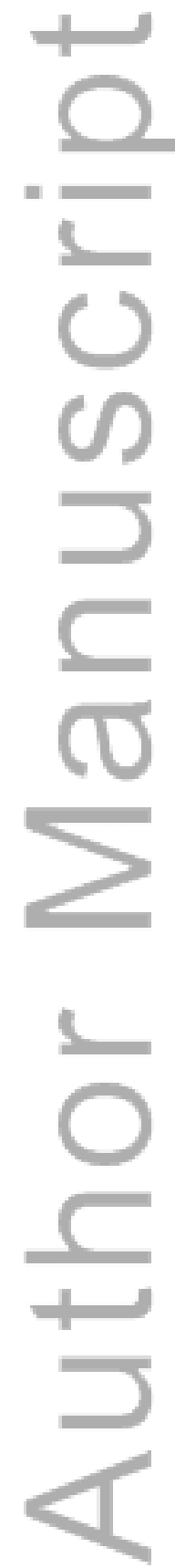

This article is protected by copyright. All rights reserved. 


\section{References}

1. Verhoef M, Lurvink M, Barf H, Post M, van Asbeck F, Gooskens R, et al. High prevalence of incontinence among young adults with spina bifida: description, prediction and problem perception. Spinal Cord 2005;43:331-40.

2. Landman G, Rappaport L, Fenton T, Levine M. Locus of control and self-esteem in children with encopresis. J Dev Behav Pediatr 1986;7:111-3.

3. Corbett P, Denny A, Dick K, Malone P, Griffin S, Stanton M. Peristeen integrated transanal irrigation system successfully treats fecal incontinence in children. J Pediatr Urol 2014;10:219-22.

4. Voskuijl W, de Lorijn F, Verwijs W, Hogeman P, Heijmans J, Makel W, et al. PEG 3350 (Transipeg) versus lactulose in the treatment of childhood functional constipation: a double blinded, randomised, controlled, multicentre trial. Gut 2004;53:1590-4.

5. Malone P, Ransley $\mathrm{P}$, Kiely E. Preliminary report: the antegrade continence enema. Lancet 1990;336:1217-8.

6. Squire R, Kiely E, Carr B, Ransley P, Duffy P. The clinical application of the Malone antegrade colonic enema. J Pediatr Surg 1993;28:10125.

7. Koyle M, Kaji D, Duque M, Wild J, Galansky G. The Malone antegrade continence enema for neurogenic and structural fecal incontinence and constipation. J Urol 1995;154:759-61.

8. Levitt M, Soffer S, Pena A. Continent appendicostomy in the bowel management of fecally incontinent children. J Pediatr Surg 1997;32:1630-3.

9. Shandling B, Chait $P$, Richards $H$. Percutaneous cecostomy: a new technique in the management of fecal incontinence. J Pediatr Surg 1996;31:534-7.

10. King S, Sutcliffe J, Southwell B, Chait P, Hutson J. The antegrade continence enema successfully treats idiopathic slow-transit constipation. J Pediatr Surg 2005;40:1935-40. 
11. Shandling B, Gilmour R. The enema continence catheter in spina bifida: successful bowel management. J Pediatr Surg 1987;22:271-3.

12. Emmanuel A. Review of the efficacy and safety of transanal irrigation for neurogenic bowel dysfunction. Spinal Cord 2010;48:664-73.

13. Vande Velde S, Van Biervliet S, Van Laecke E, De Bruyne R, Verhelst $H$, Hoebeke $P$, et al. Colon enemas for fecal incontinence in patients with spina bifida. J Urol 2013;189:300-4.

14. Pacilli M, Pallot D, Andrews A, Downer A, Dale L, Willetts I. Use of Peristeen transanal colonic irrigation for bowel management in children: a single-center experience. J Pediatr Surg 2014;49:269-72.

15. Pereira P, Salvador O, Arcas J, Urrutia J, Romera R, Monereo E.

Transanal irrigation for the treatment of neuropathic bowel dysfunction.

J Pediatr Urol 2010;6:134-8.

16. Rockwood T, Church J, Fleshman J, Kane R, Mavrantonis C, Thorson A, et al. Fecal Incontinence Quality of Life Scale: Quality of Life Instrument for Patients with Fecal Incontinence. Dis Colon Rectum 2000;43:9-17.

17. Vaizey C, Carapeti E, Cahill J, Kamm M. Prospective comparison of faecal incontinence grading systems. Gut 1999;44:77-80.

18. Agachan F, Chen T, Pfeifer J, Reissman P, Wexner S. A constipation scoring system to simplify evaluation and management of constipated patients. Dis Colon Rectum 1996;39:681-5.

19. Krogh K, Christensen P, Sabroe S, Laurberg S. Neurogenic bowel dysfunction score. Spinal Cord 2006;44:625-31.

20. Nanigian D, Nguyen T, Tanaka S, Cambio A, DiGrande A, Kurzrock E. Development and validation of the fecal incontinence and constipation quality of life measure in children with spina bifida. J Urol 2008; 180:1770-3.

21. Taskinen S, Valanne L, Rintala R. Effect of spinal cord abnormalities on the function of the urinary tract in patients with anorectal abnormalities. J Urol 2002;168:1147-9.

22. Coggrave M, Norton C, Cody J. Management of faecal incontinence and constipation in adults with central neurological diseases. Cochrane 
Database of Systematic Reviews 2014, Issue 1. Art. No.: CD002115 DOI: 10.1002/14651858.CD002115.pub5.

23. Leibold S. Achieving continence with a neurogenic bowel. Pediatr Clin N Am 2010;57:1013-25.

24. Eradi B, Hamrick M, Bischoff A, Frischer J, Helmrath M, Hall J, et al. The role of a colon resection in combination with a Malone appendicostomy as part of a bowel management program for the treatment of fecal incontinence. J Pediatr Surg 2013;48:2296-300.

25. Liptak G, Revell G. Management of bowel dysfunction in children with spinal cord disease or injury by means of the enema continence catheter. J Pediatr 1992;120:190-4.

26. Mattsson S, Gladh G. Tap-water enema for children with

myelomeningocele and neurogenic bowel dysfunction. Acta Paediatrica 2006;95:369-74.

27. Ausili E, Focarelli B, Tabacco F, Murolo D, Sigismondi M, Gasbarrini A, et al. Transanal irrigation in myelomeningocele children: an alternative, safe and valid approach for neurogenic constipation. Spinal Cord 2010;48:560-5.

28. Harari D, Norton C, Lockwood L, Swift C. Treatment of constipation and fecal incontinence in stroke patients: randomized controlled trial. Stroke 2004;35:2549-55.

29. Velde S, Biervliet S, Bruyne R, Winckel M. A systematic review on bowel management and the success rate of the various treatment modalities in spina bifida patients. Spinal Cord 2013;1-9.

30. Christensen P, Bazzocchi G, Coggrave M, Abel R, Hultling C, Krogh K, et al. A randomized, controlled trial of transanal irrigation versus conservative bowel management in spinal cord-injured patients. Gastroenterology 2006;131:738-47.

31. Matsuno D, Yamazaki Y, Shiroyanagi Y, Ueda N, Suzuki M, Nishi M, et al. The role of the retrograde colonic enema in children with spina bifida: is it inferior to the antegrade continence enema? Pediatr Surg Int 2010;26:529-33. 
Table 1 - Characteristics of patients in whom Peristeen was still being used versus those in whom Peristeen was no longer being used

\begin{tabular}{|c|c|c|}
\hline Characteristic & Still in use & No longer used \\
\hline Patients & 9 & 11 \\
\hline \multicolumn{3}{|l|}{ Gender } \\
\hline -male & 7 & 4 \\
\hline -female & 2 & 7 \\
\hline Age in years (mean, $(S D))$ & $13.4(5.8)$ & $15.5(5.0)$ \\
\hline VP shunt & 9 & 7 \\
\hline VP shunt revision(s) & 7 & 6 \\
\hline Associated anomalies & 4 & 2 \\
\hline - scoliosis & 1 & 1 \\
\hline - Arnold Chiari & 2 & 1 \\
\hline - epilepsy & 1 & 0 \\
\hline - microcephaly & 1 & 0 \\
\hline Urinary incontinence & 9 & 11 \\
\hline - ClC via urethra & 7 & 8 \\
\hline - CIC via Mitrofanoff & 0 & 2 \\
\hline - bladder augmentation & 0 & 1 \\
\hline - nil catheterisation & 2 & 0 \\
\hline \multicolumn{3}{|l|}{ Mobility } \\
\hline - walk independently & 0 & 3 \\
\hline - with with AFO & 5 & 2 \\
\hline - walk with crutches & 1 & 1 \\
\hline - wheelchair & 3 & 5 \\
\hline $\begin{array}{l}\text { Age at commencement in } \\
\text { years (mean, }(S D))\end{array}$ & $9.4(6.0)$ & $12.3(4.2)$ \\
\hline Time for training & 1 hour $(1,1 h-1 d)$ & 1 hour $(1,1 h-2 d)$ \\
\hline \multicolumn{3}{|l|}{ Instillate used } \\
\hline - water & 8 & 11 \\
\hline - saline & 1 & 0 \\
\hline
\end{tabular}

This article is protected by copyright. All rights reserved. 


\begin{tabular}{|l|l|l|}
\hline $\begin{array}{l}\text { Instillate volume in millilitres } \\
\text { (mean, (SD)) }\end{array}$ & $400(180.3)$ & $419(140.1)$ \\
\hline $\begin{array}{l}\text { Time taken to perform in } \\
\text { minutes (mean, (SD)) }\end{array}$ & $46.1(14.7)$ & $38.2(17.6)$ \\
\hline Frequency of use & 1 & \\
\hline- daily & 6 & 2 \\
\hline$-2^{\text {nd }}$ daily & 2 & 4 \\
\hline- - twice/week & $48(24-69)$ & 5 \\
\hline $\begin{array}{l}\text { Duration of use in months } \\
\text { (median, (IQR)) }\end{array}$ & $6(0.25-12){ }^{\#}$ \\
\hline $\begin{array}{l}\text { Migration to ACE } \\
\text { Degree of independence with } \\
\text { RCE }\end{array}$ & 0 & 3 \\
\hline - excellent & 0 & \\
\hline- moderate & 2 & 2 \\
\hline - dependent & 7 & 5 \\
\hline
\end{tabular}

\# $p=0.001$

VP - ventriculoperitoneal shunt, $\mathrm{ClC}$ - clean intermittent catheterisation, AFO

- ankle foot orthosis, ACE - antegrade continence enema, RCE - retrograde continence enema

This article is protected by copyright. All rights reserved. 
Table 2 - Scores of patients in whom Peristeen was still being used versus those in whom Peristeen was no longer being used

\begin{tabular}{|c|c|c|c|}
\hline Score & Still in use & No longer used & $\mathbf{p}$ \\
\hline FIQOL & $92.9(15.8)$ & $85.2(14.3)$ & 0.28 \\
\hline \multicolumn{4}{|l|}{$(29-119,29=$ poor $)$} \\
\hline St Marks Faecal Incontinence & $14.7(3.3)$ & $16.7(4.5)$ & 0.27 \\
\hline \multicolumn{4}{|l|}{$(0-24,24=$ severe $)$} \\
\hline Cleveland Clinic Constipation & $13.1(3.0)$ & $10.8(5.0)$ & 0.24 \\
\hline \multicolumn{4}{|l|}{$(0-30,30=$ severe $)$} \\
\hline Neurogenic Bowel Dysfunction & $11.8(5.1)$ & $12.5(6.8)$ & 0.78 \\
\hline$(0-47,47=$ severe $)$ & & & \\
\hline
\end{tabular}

FIQOL = Fecal Incontinence Quality Of Life; results displayed as means (SD)

This article is protected by copyright. All rights reserved. 


\section{University Library}

\section{- M M N E R VA A gateway to Melbourne's research publications}

Minerva Access is the Institutional Repository of The University of Melbourne

Author/s:

King, SK;Stathopoulos, L;Pinnuck, L;Wells, J;Hutson, J;Heloury, Y

Title:

Retrograde continence enema in children with spina bifida: Not as effective as first thought

Date:

2017-04-01

Citation:

King, S. K., Stathopoulos, L., Pinnuck, L., Wells, J., Hutson, J. \& Heloury, Y. (2017).

Retrograde continence enema in children with spina bifida: Not as effective as first thought. JOURNAL OF PAEDIATRICS AND CHILD HEALTH, 53 (4), pp.386-390. https:// doi.org/10.1111/jpc.13408.

Persistent Link:

http://hdl.handle.net/11343/292123 